\title{
Absence of bacterial colonization of the airways after therapeutic rigid bronchoscopy without stenting
}

\author{
M. Noppen ${ }^{+}$, D. Piérard*, M. Meysman ${ }^{+}$, R.V. Herreweghe ${ }^{+}$, W. Vincken ${ }^{+}$
}

\begin{abstract}
Absence of bacterial colonization of the airways after therapeutic rigid bronchoscopy without stenting. M. Noppen, D. Piérard, M. Meysman, R.V. Herreweghe, W. Vincken. (C) ERS Journals Ltd 2000.

ABSTRACT: Following airway stenting, bacterial colonization of the airways with potentially pathogenic micro-organisms occurs within 4 weeks after treatment in the majority of patients. The objective of this study was to prospectively investigate whether nonstenting therapeutic rigid bronchoscopy (using laser, cryotherapy, mechanical dilatation or debridement) is followed by airway colonization or infection.

Protected specimen brush sampling of the central airways and quantitative culture were performed immediately prior to, and 4 weeks after nonstenting therapeutic rigid bronchoscopy in 20 consecutive patients with central airway lesions.

Prior to therapeutic bronchoscopy, airway colonization/infection was present in nine of $20(45 \%)$ patients. In these nine patients, 10 different potential pathogens were identified: Streptococcus pneumoniae (four cases), Pseudomonas aeruginosa (three), Haemophilus influenzae (two), and Serratia marcescens (one). Eight of these nine patients had a history of postobstructive infections, of which three were currently being treated with antibiotics. Four weeks following therapeutic bronchoscopy, airway colonization/infection was present in five of $20(25 \%)$ patients, each of whom had airway colonization/infection prior to bronchoscopy. In three of these five patients, the same organisms were found 4 weeks after bronchoscopy as at baseline bronchoscopy. In two of five patients new organisms were identified: one case of Streptococcus viridans and one case of Haemophilus parainfluenzae, both considered to be nonpathogens. In four of nine patients with airway colonization/infection prior to bronchoscopy, the airways were clear of micro-organisms after the procedure.

The authors conclude that: 1) nonstenting therapeutic rigid bronchoscopy is not complicated by airway colonization or infection by new potential pathogens; and 2) therapeutic rigid bronchoscopy led to clearing of airway colonization/infection in almost half of the patients studied.
\end{abstract}

Eur Respir J 2000; 16: 1147-1151.

Although rigid bronchoscopy is performed less often than flexible bronchoscopy in adult pulmonary medicine, it is preferred for therapeutic intervention in the central airways, including laser treatment, cryotherapy, dilatation procedures, mechanical debridement and stenting [1].

The authors recently showed that following airway stenting, bacterial colonization of the airways with potentially pathogenic micro-organisms (PPM's) occurs within 3-4 weeks of the procedure in the majority of treated patients.

The mechanism of this airway colonization after stenting remains unclear. One possible explanation is contamination of the airways via the rigid bronchoscope itself, by translocation of bacteria that may already colonize the oropharynx and/or proximal airway [2].

In order to confirm or refute this hypothesis, the authors performed quantitative protected specimen brush sampling of the central airways before and after therapeutic rigid bronchoscopy (laser therapy, cryotherapy, mechanical debridement and dilatation), excluding airway stenting, in 20 consecutive patients referred for endoscopic treatment of central airway lesions.
${ }^{4}$ Respiratory Division and *Microbiology Dept, Academic Hospital AZ-VUB, Free University of Brussels, Brussels, Belgium.

Correspondence: M. Noppen

Respiratory Division

Academic Hospital AZ-VUB

101, Laarbeeklaan

B-1090 Brussels

Belgium

Fax: 3224776019

Keywords: Airway infection cryotherapy

laser therapy

mechanical dilatation

protected specimen brush sampling

rigid bronchoscopy

Received: May 292000

Accepted after revision August 252000
Materials and methods

Patients

Twenty consecutive patients (age: $60.1 \pm 12.6$ yrs, range: 38-83 yrs) with central airway disease referred for therapeutic rigid bronchoscopy, without airway stenting, were studied over a one-year period. All patients agreed to a follow-up visit at the centre 4 weeks after treatment.

Patient characteristics, airway disease and location, type of bronchoscopic treatment, history of recent (airway or pulmonary) infection prior to bronchoscopy, and antibiotic treatment at the time of bronchoscopy are shown in table 1.

All the patients consented to the study protocol which was approved by the Ethics Committee of the hospital.

\section{Methods}

Study design. The purpose of the present study was to investigate whether nonstenting therapeutic bronchoscopy is followed by airway colonization/infection. For this 
purpose, protected specimen brush sampling with quantitative cultures of the central airways was performed immediately prior to, and 4 weeks after therapeutic bronchoscopy in 20 consecutive patients with central airway lesions. At the time of the visit at 4 weeks, all patients were interviewed on colonization/infection-related events during the previous month (i.e. foul breath, changes in sputum purulence, antibiotic use, other clinical signs of infection, etc.).

Specimen collection. Immediately prior to therapeutic bronchoscopic intervention, specimens for microbiological analysis were obtained from patients in the supine position, under total intravenous anaesthesia using propofol, alfentanyl or remifentanyl, and atracurium. Patients were intubated with a rigid bronchoscope (Efer Dumon, La Ciotat, France or Storz, Tuttlingen, Germany), through which ventilation and oxygenation were assured using high-frequency jet ventilation with variable inspiratory oxygen fractions $\left(F \mathrm{I}, \mathrm{O}_{2}\right)$.

The rigid bronchoscope was positioned proximally to the airway lesion. Immediately thereafter, a flexible bronchoscope (Olympus Type 20 D; Olympus, Tokyo, Japan) was passed through the rigid instrument and advanced through the airway stenosis when present. The tip of the flexible bronchoscope was immobilized immediately distal to the lesion. A plugged telescoping catheter brush (Model 130; Mill-Rose Laboratories, Mentor, OH, USA), was passed through the working channel and advanced $2 \mathrm{~cm}$ beyond the tip of the flexible bronchoscope. After ejection of the distal plug by protruding the inner cannula, the brush was advanced beyond the tip of the inner cannula, gently rotated against the airway wall or, when present, in visible secretions. It was then retracted a few centimetres into the inner cannula. The catheter was then retracted out of the flexible bronchoscope. If the flexible bronchoscope could not be passed through the airway stenosis because of a very small residual lumen or because of jeopardized ventilation and oxygenation, the tip of the bronchoscope was fixed immediately proximal to the stenosis. The catheter was then passed through the stenosis, and sampling was performed as described previously.

Four weeks after the therapeutic rigid bronchoscopy, the patients were examined in the outpatient clinic. Flexible bronchoscopy was performed transorally with the patient in the sitting position. After local anaesthesia of the oropharynx with $10 \%$ lignocaine spray, and of the larynx with $4 \mathrm{~mL}$ of $2 \%$ lignocaine solution, an Olympus flexible bronchoscope was introduced. After inspection of the airways, protected specimen brush sampling was performed immediately distal to the (previous) location of the stenosis or lesion. If secretions were present, sampling was performed by rubbing the naked brush in these secretions. If no secretions were visible, sampling was performed against the airway wall.

Processing of brush specimens. The distal portions of the catheters were wiped clean with $70 \%$ ethanol immediately after retraction from the bronchoscope, the brushes were cut with sterile scissors, and placed into a sterile tube containing $1 \mathrm{~mL}$ of sterile saline, and agitated for $1 \mathrm{~min}$. The tube was immediately transported to the laboratory. Volumes of $0.1 \mathrm{~mL}$ and $0.01 \mathrm{~mL}$ of the original solution were inoculated on the following agar media for quantitative culture and identification: horse blood agar supplemented with $\mathrm{X}$ and $\mathrm{V}$ factors incubated in $5 \% \mathrm{CO}_{2}$ at $37^{\circ} \mathrm{C}$, MacConkey agar, mannitol salt agar, charcoal yeast agar and Sabouraud agar incubated under aerobic conditions at $37^{\circ} \mathrm{C}$. If positive, identification by standard laboratory methods and counting of colony-forming units per millilitre $\left(\mathrm{cfu} \cdot \mathrm{mL}^{-1}\right)$ were performed for each species. A cut-off value of $\geq 1 \times 10^{2} \mathrm{cfu} \cdot \mathrm{mL}^{-1}$ was considered diagnostic for airway colonization [3]. Although cut-off values of $\geq 1 \times 10^{3} \mathrm{cfu} \cdot \mathrm{mL}^{-1}$ (for brush samples) and

Table 1. - Patient characteristics at the time of baseline brush sampling

\begin{tabular}{|c|c|c|c|c|c|c|c|}
\hline $\begin{array}{l}\text { Patient } \\
\text { number }\end{array}$ & Sex & $\begin{array}{l}\text { Age } \\
\text { yrs }\end{array}$ & Airway disease & Location & $\begin{array}{l}\text { Bronchoscopic } \\
\text { treatment }\end{array}$ & $\begin{array}{l}\text { Previous } \\
\text { infections }\end{array}$ & $\begin{array}{l}\mathrm{AB} \theta \text { at time of } \\
\text { bronchoscopy }\end{array}$ \\
\hline 1 & $\mathrm{~F}$ & 52 & Metastastic melanoma & $\mathrm{T}$ & $\mathrm{L}, \mathrm{C}$ & - & - \\
\hline 2 & $\mathrm{M}$ & 70 & Endobronchial lipoma & LUL & $\mathrm{L}, \mathrm{MR}$ & + & - \\
\hline 3 & $\mathrm{~F}$ & 79 & Pits & $\mathrm{T}$ & $\mathrm{L}, \mathrm{D}$ & - & - \\
\hline 4 & $\mathrm{~F}$ & 59 & CIS & RUL & $\mathrm{C}$ & - & - \\
\hline 5 & $\mathrm{~F}$ & 38 & Pits & $\mathrm{T}$ & $\mathrm{L}, \mathrm{D}$ & + & - \\
\hline 6 & $\mathrm{M}$ & 59 & Endobronchial lipoma & RMB & $\mathrm{L}, \mathrm{MR}$ & + & - \\
\hline 7 & $\mathrm{M}$ & 52 & Metastatic rectal carcinoma & RMB & $\mathrm{L}$ & - & - \\
\hline 8 & M & 61 & NSCLC & RMB, carina & $\mathrm{L}$ & - & - \\
\hline 9 & M & 40 & Hamartoma & RUL & $\mathrm{L}, \mathrm{MR}$ & + & - \\
\hline 10 & M & 63 & NSCLC & RIB & $\mathrm{L}$ & + & + \\
\hline 11 & $\mathrm{M}$ & 72 & NSCLC & LMB, LLL & $\mathrm{L}$ & + & + \\
\hline 12 & M & 48 & Burn & $\mathrm{T}$ & $\mathrm{L}$ & + & + \\
\hline 13 & M & 83 & NSCLC & RMB & $\mathrm{L}, \mathrm{MR}$ & + & - \\
\hline 14 & $\mathrm{~F}$ & 58 & NSCLC & RIB & $\mathrm{L}$ & - & - \\
\hline 15 & $\mathrm{M}$ & 63 & CIS & $\mathrm{T}$ & $\mathrm{C}$ & - & - \\
\hline 16 & $\mathrm{~F}$ & 42 & Haemangioma & $\mathrm{T}$ & $\mathrm{C}$ & - & - \\
\hline 17 & M & 69 & CIS & $\mathrm{T}$ & $\mathrm{C}$ & - & - \\
\hline 18 & $\mathrm{M}$ & 59 & NSCLC & RUL & $\mathrm{L}$ & + & - \\
\hline 19 & $\mathrm{~F}$ & 77 & Cong. Subglottic stenosis & $\mathrm{T}$ & $\mathrm{L}$ & - & - \\
\hline 20 & M & 58 & CIS & LUL & $\mathrm{C}$ & - & - \\
\hline
\end{tabular}

F: female; M: male; Pits: post-intubation tracheal stenosis; NSCLC: non small-cell lung cancer; CIS: carcinoma in situ; T: trachea; L/ RUL: left/right upper lobe; L/RMB: left/right main bronchus; RIB: right intermediate bronchus; L: laser therapy; C: cryotherapy; D: mechanical balloon dilatation; MR: mechanical forceps resection; $\mathrm{AB} \theta$ : antibiotic treatment. 
$1 \times 10^{4} \mathrm{cfu} \cdot \mathrm{mL}^{-1}$ (for bronchoalveolar lavage samples) are considered diagnostic for "infection" a cut-off value of $\leq 1 \times 10^{2} \mathrm{cfu} \cdot \mathrm{mL}^{-1}$ obtained via brush sampling of the airways is suggestive of "colonization" [3].

Quality assessment of the brush samples by microscopic cell count was performed as described by MerTENs et al. [4], on a cytospin preparation of $140 \mu \mathrm{L}$ of the original fluid, microscopic scoring of cell counts was performed, including the number of squamous epithelial cells $(<1 \%$ was considered as uncontaminated lower airway sample) and the number of bronchial columnar cells, macro-

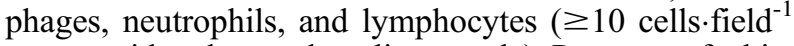
was considered a good quality sample). Presence of white blood cells was expressed semiquantitatively: $+:$ 1-5/ high-power field (HPF); ++: 6-10/HPF; +++: 11-20/ $\mathrm{HPF}$; and ++++ : $>20 / \mathrm{HPF}$.

\section{Results}

All interventional procedures were uneventful. There were no major complications or procedure-related deaths. All the patients were discharged from hospital after 24 or $48 \mathrm{~h}$. Patient demographics, airway disease, treatment, and history are summarized in table 1 .

All brush samples were of good quality in terms of percentage epithelial cells on cytospin preparations $(<1 \%)$ [4]. Four samples showed $<10$ cells.field $^{-1}$, suggesting inadequate sampling. However, because of the low $(<1 \%)$ percentage of epithelial cells, these samples were included for analysis.

The results of brush sampling are shown in table 2 . In nine of 20 patients $(45 \%)$ baseline samples showed airway colonization/infection with potentially pathogenic micro-organisms including: Pseudomonas aeruginosa (three cases), Streptococcus pneumoniae (four), Haemophilus influenzae (two) and Serratia marcescens (one). Eight of these nine patients (four with malignant, four with benign disease) had a previous history of (postobstructive) infection prior to intervention; three of the eight patients were receiving antibiotic treatment at the time of diagnosis (patients number (No.) 10, 11, 12) because of clinical signs of infection. Despite antibiotic treatment, brush cultures in patients No. 10 and 12 were positive, probably because the empirical choice of antibiotics (ciprofloxacin in patient No. 12 and amoxicillin-clavulanic acid in patients No. 10 and 12) was not optimal (presence of $P$. aeruginosa in patient No. 10, and multiresistant $P$. aeruginosa and $S$. marcescens in patient No. 12). On the basis of brush culture results, patient No. 10 had treatment changed to ciprofloxacin $500 \mathrm{mg}$ b.i.d. for 10 days, and patient No. 12 to nebulized tobramycin $80 \mathrm{mg}$ b.i.d. for 10 days. At the time of the 4-week brush sampling, no antibiotics were being taken by any patient. In patient No. 11, treated with cefuroxime-axetil, baseline brush sampling was negative.

Four weeks after bronchoscopy, brush sampling showed airway colonization/infection in only five of $20(25 \%)$ patients. In three of these five patients the same organisms were recovered as before bronchoscopy ( $S$. pneumoniae in two cases, $P$. aeruginosa in one case). In the fourth patient (No. 12), S. viridans was found in addition to P. aeruginosa and $S$. marcescens, and in patient No. 13, $S$. pneumoniae was replaced by $H$. parainfluenzae.

Thus, (No. 12 and 13) new organisms were identified in only two patients 4 weeks after the bronchoscopic procedure, but each (S. viridans, $H$. parainfluenzae) was considered to be nonpathogenic. In four of the nine patients

Table 2. - Results of brush sampling at baseline, and 4 weeks after bronchoscopic treatment

\begin{tabular}{|c|c|c|c|c|c|c|c|c|c|c|}
\hline \multirow{2}{*}{$\begin{array}{l}\text { Patient } \\
\text { No. }\end{array}$} & \multicolumn{4}{|c|}{ Baseline brushing } & \multicolumn{4}{|c|}{ Baseline after 4 weeks } & \multirow{2}{*}{$\begin{array}{l}\text { History } \\
\text { previous } \\
\text { infection }\end{array}$} & \multirow{2}{*}{$\begin{array}{l}\mathrm{AB} \text { at } \\
\text { baseline }\end{array}$} \\
\hline & WBC & Ep \% & $\mathrm{C} / \mathrm{fld}$ & Culture $\mathrm{mL}^{-1}$ & WBC & Ep \% & $\mathrm{C} / \mathrm{fld}$ & Culture $\mathrm{mL}^{-1}$ & & \\
\hline 1 & 0 & $<1$ & 10 & - & + & $<1$ & 50 & - & - & - \\
\hline 2 & 0 & $<1$ & 10 & $1 \times 10^{4} \mathrm{H}$. influenzae & 0 & $<1$ & 10 & - & + & - \\
\hline 3 & + & $<1$ & 100 & - & + & $<1$ & 50 & - & - & - \\
\hline 4 & 0 & $<1$ & 50 & - & + & $<1$ & 100 & - & - & - \\
\hline 5 & ++ & $<1$ & 100 & $2 \times 10^{4} P$. aeruginosa & + & $<1$ & 50 & - & + & - \\
\hline 6 & ++ & $<1$ & 100 & $>1 \times 10^{5} S$. pneumoniae & + & $<1$ & 10 & - & + & - \\
\hline 7 & + & $<1$ & 50 & - & + & $<1$ & 100 & - & - & - \\
\hline 8 & ++ & $<1$ & $>100$ & $>1 \times 10^{5} S$. pneumoniae & + & $<1$ & 100 & $2 \times 10^{4} \mathrm{~S}$. pneumoniae & - & - \\
\hline 9 & +++ & $<1$ & $>100$ & $1 \times 10^{4} \mathrm{H}$. influenzae & + & $<1$ & 100 & - & + & - \\
\hline 10 & +++ & $<1$ & $>100$ & $>1 \times 10^{5} P$. aeruginosa & +++ & $<1$ & $>100$ & $2 \times 10^{4} P$. aeruginosa & + & + \\
\hline 11 & ++++ & $<1$ & $>100$ & - & ++ & $<1$ & $>100$ & - & + & + \\
\hline 12 & ++++ & $<1$ & $>100$ & $\begin{array}{l}>1 \times 10^{5} P . \text { aeruginosa } \\
>1 \times 10^{5} \mathrm{~S} . \text { marcescens }\end{array}$ & ++++ & $<1$ & $>100$ & $\begin{array}{c}>1 \times 10^{5} \mathrm{~S} . \text { marcescens } \\
>1 \times 10^{5} \mathrm{P} . \text { aeruginosa } \\
\quad 1 \times 10^{5} \mathrm{~S} . \text { viridans }\end{array}$ & + & + \\
\hline 13 & +++ & $<1$ & $>100$ & $1 \times 10^{2} S$. pneumoniae & ++ & $<1$ & $>100$ & $2 \times 10^{3} \mathrm{H}$. parainfluenzae & + & - \\
\hline 14 & + & $<1$ & $<10$ & - & ++ & $<1$ & 50 & - & - & - \\
\hline 15 & + & $<1$ & $<10$ & - & 0 & $<1$ & 10 & - & - & - \\
\hline 16 & + & $<1$ & 50 & - & 0 & $<1$ & $<10$ & - & & \\
\hline 17 & 0 & $<1$ & 10 & - & 0 & $<1$ & 50 & - & - & - \\
\hline 18 & +++ & $<1$ & 100 & $2 \times 10^{2} S$. pneumoniae & ++ & $<1$ & $>100$ & $1 \times 10^{4} S$. pneumoniae & + & - \\
\hline 19 & + & $<1$ & 10 & - & + & $<1$ & $<10$ & - & - & - \\
\hline 20 & ++ & $<1$ & 50 & - & ++ & $<1$ & 100 & - & - & - \\
\hline
\end{tabular}

WBC: white blood cells; WBC+: 1-5/high power field (HPF); WBC++: 6-10 WBC/HPF; WBC+++: 11-20 WBC/HPF; WBC++++: $>20 \mathrm{WBC} / \mathrm{HPF}$; C/fld: cells/fields; Ep: epithelial cells; ABq: antibiotic treatment. No patient took antibiotics at the 4-week PSB sampling. 
with airway colonization/infection prior to therapeutic bronchoscopy, the airways were clear of micro-organisms 4 weeks after the procedure. No patient reported the use of antibiotics in the follow-up period. In eight patients further flexible bronchoscopy was performed within the 4-week follow-up period.

\section{Discussion}

In this prospective study, it was shown that rigid therapeutic bronchoscopy including laser therapy, cryotherapy, dilatation and mechanical debridement is not complicated by bacterial airway colonization or infection by potentially new pathogens.

Insertion of a rigid bronchosope inevitably necessitates passage through the oral cavity, which is colonized by a variety of nonpathogenic and even potentially pathogenic micro-organisms [5]. This mechanism may have been (one of) the cause(s) of the airway colonization which was observed after airway stenting via the rigid bronchoscope [2]. The possibility of infection after therapeutic rigid bronchoscopy without the insertion of airway stents has prompted some endoscopists in the past to use prophylactic antibiotics [6-8], although others use antibiotics only if mucopurulent secretions are identified during the procedure [9] pending the results of further studies.

Much of the previous information on the infectious complications of rigid bronchoscopy is anecdotal; in one series fever was observed in $46 \%$ of 52 patients (with positive blood cultures in one-third of the patients with fever) [10], and Tiтche [11] noted fever in 38\% of 361 patients after rigid bronchoscopy. Anaesthetic and bronchoscopic (patient preparation, bronchoscopy procedure) techniques have however, changed considerably since the 1940-1960s, and no recent information is available.

In the series of 20 consecutive study patients undergoing rigid therapeutic bronchoscopy (excluding stenting) for a variety of central airway lesions, no new potential pathogens were identified at 4 weeks after the procedure. Two new nonpathogenic organisms were present in only two $(10 \%)$ patients (No. 12 and 13), after the procedure. This is in contrast to previous findings in patients with airway stents, where new organisms were identified in 7 of 14 patients $(50 \%)$, by brush sampling, 3-4 weeks after the procedure. Furthermore, in the stented patients, various potentially pathogenic organisms were cultured [2].

The presence of micro-organisms on baseline brush sampling, was however comparable in both the previous patients presenting [2] and the current nonstented group; five of $14(36 \%)$ versus nine of $20(45 \%)$ positivity. In contrast with the stented group in a previous paper [2], baseline brush specimen positivity seemed to be related to a history of postobstructive infections, although this difference may be due to the small sample size of the stented group. Nevertheless, in the majority (four out of six, $67 \%$ ) of the patients with nonsmall cell lung cancer airway colonization was present at baseline. Distal bacterial airway colonization is frequently observed in patients with bronchial carcinoma, CABELlo et al. [3] found that $42 \%$ of patients were colonized using brush and lavage sampling, the majority with nonpathogens. Below the obstructive lesion, however, other micro- organisms may be isolated, mostly potential pathogens [12]. The findings of the present study are therefore, in agreeement with the literature.

In contrast to the previous study [2], therapeutic nonstenting bronchoscopy in the current population seemed to have had a beneficial effect on airway colonization or infection, since in four of the nine patients with baseline positive brush specimens, significant growth of microorganisms was no longer present after the procedure; in the stented group, new (and potentially pathogenic) micro-organisms were present within 3-4 weeks after the stenting procedure [2]. This suggests that the presence of a stent in itself, and not the bronchoscopic procedure used to insert it, is the probable cause of airway colonization/infection, since in both comparable patient groups therapeutic bronchoscopy resolved any airway obstruction, when present. Inherent "stent-related" mechanisms, such as irregularities on the internal stent surface (as with colonization of endotracheal tubes) [13], bacterial cell wall material promoting bacterial binding to the stent (as has been shown for P. aeruginosa) [2, 14], or stent-induced mucus-retention due to interruption of mucociliary clearance [15] or increased "reflex" mucussecretion [16] may play a role.

Two limitations of this study are that no blood cultures were taken, and that only one control brush sampling was performed at 4 weeks after therapeutic bronchoscopy. No blood cultures were taken because: 1) the main purpose of this study was to investigate microbiological events on the level of the airways, for comparison with the authors previous work [2] in stented patients; and 2) because the majority of the patients were referred from other institutions making regular follow-up blood cultures with centralized processing impossible to achieve.

The 4-week delay between brush samplings may have underestimated the occurrence of colonization/infectious events. However, this 4 -week period was chosen for easy comparison with the authors previous study in stented patients [2]. Also, all the patients were severely ill with symptoms due to severe major airway disease. Because of this, and because most patients were referred from other institutions, earlier and repeated (e.g. weekly) sampling was not feasible. Hence, no precise information on the occurrence or resolution of colonization/infection in treated patients can be derived from this study. Nevertheless, all patients were seen again 4 weeks after the therapeutic bronchoscopy, and interviewed on events, possibly related to, or suggestive of, colonization/infection, during the previous month. No patient mentioned foul breath, increased sputum purulence, fever, antibiotic usage, or other signs of infection.

The authors conclude that nonstenting therapeutic rigid bronchoscopy using laser, cryotherapy, mechanical dilatation and debridement is not complicated by bacterial airway colonization, as measured four weeks after the therapeutic procedure. Furthermore, there was no history of events suggesting colonization or infection during the follow-up period. This is in striking contrast with the previous observation that rigid bronchoscopy followed by airway stenting is followed by significant airway colonization/infection by potentially pathogenic micro-organisms, suggesting that the stent itself, and not the rigid bronchoscopy used for its insertion, is the probable cause of airway colonization/infection. Furthermore, baseline 
airway colonization was present almost exclusively in patients with a previous history of (postobstructive) infection, In these cases, quantitative protected specimen brush sampling may direct antibiotic therapy, although in the majority of patients therapeutic bronchoscopy alone was able to resolve the infection.

Acknowledgements. The authors would like to show their appreciation for the secretarial skills of L.V. Gijseghem.

\section{References}

1. Helmers RA, Sanderson DR. Rigid bronchoscopy, the forgotten art. Clin Chest Med 1995; 16: 393-399.

2. Noppen M, Piérard D, Meysman M, Claes I, Vincken W. Bacterial colonization of central airways after stenting. Am J Respir Crit Care Med 1999; 160: 672-677.

3. Cabello H, Torres A, Celis R, et al. Bacterial colonization of distal airways in healthy subjects and chronic lung disease: a bronchoscopic study. Eur Respir J 1997; 10: $1137-1144$.

4. Mertens AH, Nagler JM, Galdermans DI, Slabbynck HA, Weise B, Coolen D. Quality assessment of protected specimen brush samples by microscopic cell count. Am J Respir Crit Care Med 1998; 157: 1240-1243.

5. Bartlett JG, Alexander J, Mayhew J, Sullivan-Sigler N, Gorbach SL. Should fiberoptic bronchoscopy samples be cultured? Am Rev Respir Dis 1976; 144: 73-78.
6. Simpson GT, Strong MS, Healy GB, Shapshay SM, Vaughan CW. Predictive factors of succes or failure in the endoscopic management of laryngeal and tracheal stenosis. Ann Otol Rhinol Laryngol 1982; 91: 384-388.

7. Friedman EM, Healy GB, McGill TJ. Carbon dioxide laser management of subglottic and tracheal stenosis. Otolaryngol Clin North Am 1983; 16: 871-877.

8. Shapshay SM, Beamis JF, Dumon JF. Total cervical tracheal stenosis: treatment by laser, dilation and stenting. Ann Otol Rhinol Laryngol 1989; 98: 890-895.

9. Mehta AC, Harris RJ, De Boer GE. Endoscopic management of benign airway stenosis. Clin Chest Med 1995; 16: 401-413.

10. Burman SO. Bronchoscopy and bacteriemia. $J$ Thorac Cardiovasc Surg 1960; 40: 635-639.

11. Titche LL. Postbronchoscopic reactions. Ann Otol 1945; 54: 568-569.

12. Yuang Shuang L, Pan-Chyr Y, Zeg Guang W, et al. The bacteriology of obstructive pneumonitis. Am J Respir Crit Care Med 1994; 149: 1648-1653.

13. Colice GL. Technical standards for tracheal tubes. Clin Chest Med 1991; 12: 433-448.

14. Costerton JW, Irwin RT. The bacterial glycocalyx in nature and disease. Annu Rev Microbiol 1981; 35: 299324.

15. Freitag L, Eicker K, Donovan TJ, Dimov D. Mechanical properties of airway stents. J Bronchol 1995; 2: 270-278.

16. Levine SA, Niederman MS. The impact of tracheal intubation on host defences and risks for nosocomial pneumonia. Clin Chest Med 1991; 12: 523-543. 